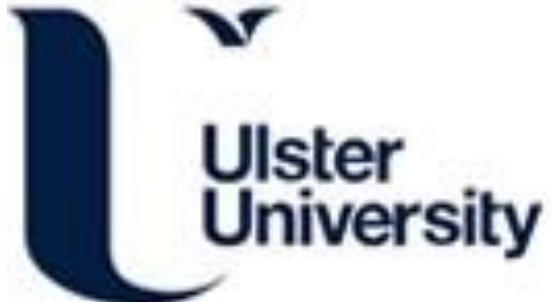

\section{Systemic capabilities: the source of IT business value}

Cao, G., Duan, Y., Cadden, T., \& minocha, S. (2016). Systemic capabilities: the source of IT business value. Information Technology and People, 29(3), 556-579. https://doi.org/10.1108/ITP-05-2014-0090

Link to publication record in Ulster University Research Portal

\section{Published in:}

Information Technology and People

Publication Status:

Published (in print/issue): 01/08/2016

DOI:

10.1108/ITP-05-2014-0090

\section{Document Version}

Author Accepted version

\section{General rights}

Copyright for the publications made accessible via Ulster University's Research Portal is retained by the author(s) and / or other copyright owners and it is a condition of accessing these publications that users recognise and abide by the legal requirements associated with these rights.

\section{Take down policy}

The Research Portal is Ulster University's institutional repository that provides access to Ulster's research outputs. Every effort has been made to ensure that content in the Research Portal does not infringe any person's rights, or applicable UK laws. If you discover content in the Research Portal that you believe breaches copyright or violates any law, please contact pure-support@ulster.ac.uk. 


\section{e emeraldinsight}

\section{Information Technology \& People}

Systemic capabilities: the source of IT business value

Guangming Cao Yanqing Duan Trevor Cadden Sonal Minocha

\section{Article information:}

To cite this document:

Guangming Cao Yanqing Duan Trevor Cadden Sonal Minocha , (2016)," Systemic capabilities: the source of IT business value ", Information Technology \& People, Vol. 29 Iss 3 pp. 556 - 579

Permanent link to this document:

http://dx.doi.org/10.1108/ITP-05-2014-0090

Downloaded on: 15 March 2017, At: 02:59 (PT)

References: this document contains references to 88 other documents.

To copy this document: permissions@emeraldinsight.com

The fulltext of this document has been downloaded 319 times since 2016*

\section{Users who downloaded this article also downloaded:}

(2016),"Organizational structure and enterprise systems implementation: Theoretical measures and a benchmark for customer teams", Information Technology \&amp; People, Vol. 29 Iss 3 pp. 527-555 http://dx.doi.org/10.1108/ITP-04-2014-0076

(2016),"The effects of relationship maintenance and relationship investment on self-service technology relationship performance", Information Technology \&amp; People, Vol. 29 Iss 3 pp. 496-526 http://dx.doi.org/10.1108/ITP-08-2014-0171

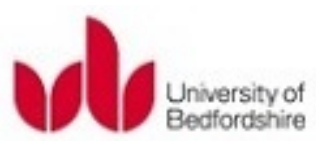

\section{Learning Resource}

Access to this document was granted through an Emerald subscription provided by emeraldsrm: 281408 []

\section{For Authors}

If you would like to write for this, or any other Emerald publication, then please use our Emerald for Authors service information about how to choose which publication to write for and submission guidelines are available for all. Please visit www. emeraldinsight.com/ authors for more information.

\section{About Emerald www.emeraldinsight.com}

Emerald is a global publisher linking research and practice to the benefit of society. The company manages a portfolio of more than 290 journals and over 2,350 books and book series volumes, as well as providing an extensive range of online products and additional customer resources and services.

Emerald is both COUNTER 4 and TRANSFER compliant. The organization is a partner of the Committee on Publication Ethics (COPE) and also works with Portico and the LOCKSS initiative for digital archive preservation. 
*Related content and download information correct at time of download. 
ITP

29,3

\section{6}

Received 2 May 2014

Revised 7 January 2015

2 July 2015

29 July 2015

5 August 2015

Accepted 10 August 2015

\title{
Systemic capabilities: the source of IT business value
}

\author{
Guangming Cao and Yanqing Duan \\ Department of Management and Business Systems, \\ University of Bedfordshire, Luton, UK \\ Trevor Cadden \\ Department of Management and Leadership, University of Ulster, \\ Newtownabbey, UK, and \\ Sonal Minocha \\ Department of Management and Business Systems, \\ University of Bedfordshire, Luton, UK
}

\begin{abstract}
Purpose - The purpose of this paper is to develop, and explicate the significance of the need for a systemic conceptual framework for understanding IT business value.

Design/methodology/approach - Embracing a systems perspective, this paper examines the interrelationship between IT and other organisational factors at the organisational level and its impact on the business value of IT. As a result, a systemic conceptual framework for understanding IT business value is developed. An example of enhancing IT business value through developing systemic capabilities is then used to test and demonstrate the value of this framework.

Findings - The findings suggest that IT business value would be significantly enhanced when systemic capabilities are generated from the synergistic interrelations among IT and other organisational factors at the systems level, while the system's human agents play a critical role in developing systemic capabilities by purposely configuring and reconfiguring organisational factors. Practical implications - The conceptual framework advanced provides the means to recognise the significance of the need for understanding IT business value systemically and dynamically. It encourages an organisation to focus on developing systemic capabilities by ensuring that IT and other organisational factors work together as a synergistic whole, better managing the role its human agents play in shaping the systems interrelations, and developing and redeveloping systemic capabilities by configuring its subsystems purposely with the changing business environment.

Originality/value - This paper reveals the nature of systemic capabilities underpinned by a systems perspective. The resultant systemic conceptual framework for understanding IT business value can help us move away from pairwise resource complementarity to focusing on the whole system and its interrelations while responding to the changing business environment. It is hoped that the framework can help organisations delineate important IT investment considerations and the priorities that they must adopt to create superior IT business value.
\end{abstract}

Keywords IT capability, IT business alignment/value, Information system effectiveness, Dynamic capabilities/relationships/perspective

Paper type Conceptual paper

\section{Introduction}

Information technology (IT) has become "a ubiquitous and increasingly significant part of the fabric of most organizations" (Doherty et al., 2010, p. 116) and IT investments

have been increased by organisations in anticipation of significant performance improvements (Cha et al., 2009). However, understanding how IT creates business value has been a complex issue (Farbey et al., 1994; Melville et al., 2004) and still remains a challenging task (Kohli and Grover, 2008; Schwarz et al., 2010), 
evidenced by widespread IT implementation failures (Clegg et al., 1997; Kling, 2003; Shpilberg et al., 2007).

Considerable research has been conducted conceptually and empirically on how IT creates business value (e.g. Melville et al., 2004; Grover and Kohli, 2012; Dutta et al., 2014). One important theme emerging from the literature is that IT creates business value when IT is aligned with, or complementary to, organisational strategy (e.g. Oh and Pinsonneault, 2007; Drnevich and Croson, 2013), process (e.g. Mishra et al., 2007; Radhakrishnan et al., 2008; Gimun et al., 2011), structure (e.g. Andersen and Segars, 2001; Kearns and Sabherwal, 2007), culture (e.g. Bradley et al., 2006; Ifinedo, 2007), or operational aspects (e.g. Wagner et al., 2014). Such understandings are often underpinned by the resource-based view (RBV) of the firm or contingency theory, and conceived and examined based on resource complementarities (Wade and Hulland, 2004) or alignments that are mainly pairwise relationships (Cao, 2010). However, they are rarely underpinned by a systems perspective.

Systems concepts (e.g. Ackoff, 1971; Churchman, 1971), although difficult to apply, can "help managers address complex problem situations" (Jackson, 2006, p. 647). Viewed from a systems perspective, IT is an integral part of an organisation as a system. As a result, IT business value needs to be understood at the level of the whole system (Leavitt and Whisler, 1958; Scott-Morton, 1995; Volkoff et al., 2007). For example, in the context of multinational enterprise and foreign direct investment, Pitelis and Teece (2010) stress the significance of "system-wide value creation" through "interrelated, co-determined and co-evolving" activities, while Kling (2003, p. 395) from the IT professionals' view emphasises the need to understand "the relationships between IT configurations, socio-technical interventions, social behavior of other participants in different roles, and the dynamics of organizational and social change". Although these studies are neither particularly on the topic of IT business value nor underpinned by a systems perspective, the systemic approach that they have embraced is clearly discernible and generally applicable to research in the IT context.

It can be argued that understanding IT business value without a systems perspective is likely to be incomplete as the focus is often on subsystem activities. So far, however, only a few articles have specifically touched on the importance of understanding IT business value holistically (e.g. Brynjolfsson and Hitt, 2000; Cao et al., 2011; Wiengarten et al., 2013). To the best of the researchers' knowledge, no research has developed a conceptual framework underpinned by a systems perspective for understanding IT business value. This knowledge gap is likely to constrain how we conceptualise IT business value and limit an organisation's ability to realise the benefits from its IT investment, evidenced by frequent IT implementation failures discussed by prior research (Clegg et al., 1997; Kling, 2003; Shpilberg et al., 2007).

The aim here is therefore to reduce this knowledge gap by understanding how IT interrelates with other organisational factors to create business value, drawing on a systems perspective. Specifically, this paper develops a new concept to explicate the nature and essence of IT business value, that is, systemic capabilities that can be broadly defined as emergent systems abilities generated at the systems level from synergistic interrelations among IT and other systems elements within an organisation as a system. Furthermore, this paper develops a systemic conceptual framework for understanding IT business value, which moves away from pairwise resource complementarity to focusing on the whole system and its interrelations while responding to the changing business environment. It is hoped that the proposed systemic framework can help organisations delineate important IT investment 
ITP

29,3

558

considerations and the priorities that they must adopt to create superior IT business value.

The remainder of this paper proceeds as follows. The next section provides a review of the literature on systems concepts and IT business value, emphasising the need for understanding IT business value systemically. The subsequent section develops the concept of systemic capabilities; based on which, propositions regarding IT business value are developed. An example of how an organisation creates IT business value is then presented to provide provisional supporting evidence for the research propositions. The paper concludes with contributions to research and practice, and limitations and directions for future research.

\section{Literature review}

In order to establish the need for understanding IT business value systemically and lay the foundation for further discussion and conceptual development, this section builds on systems concepts to understand the key characteristics of IT business value and critique literature on IT business value. To begin with, the systems concepts used in this research are defined.

\subsection{Systems concepts and IT business value}

An organisation can be viewed as a system composed of interrelated subsystems or systems elements such as organisational members, strategy, structure, process, culture, and IT, separated by a boundary from its environment.

A system has the following qualities. The behaviour of each element of the system has an effect on the behaviour of the whole; the behaviour of the elements and their effects on the whole are interdependent; and each element of the system is affected by at least one other element in the system (Ackoff, 1981). As a result of the interrelations among systems elements, novel properties will emerge at the level of the whole system, which are not present in the elements (Ackoff, 1971; Churchman, 1971).

From this view, an organisation's IT business value is the behaviour of the whole system rather than that of systems elements, such as the pairwise relationship between IT and another organisational factor. Consequently, understanding IT business value based on pairwise relationship seems to be extremely problematic since systems properties emerge only at the level of the whole rather than at the subsystems level. It can be conjectured that in order for a system to perform well, IT and other systems elements need to work together synergistically to generate certain systems-level properties. This conjecture provides the basis for examining how extant research understands IT-related synergies and IT business value.

\subsection{IT-related synergy and IT business value}

The concept of synergy has been used to understand how business value can be created from the relationship between IT and another organisational factor. In the IT context, synergy refers to the joint result that can only be obtained when IT and another organisational factor work together at either the corporate or business level. A number of studies recognise that IT-related synergies can be created in the forms of organisational capabilities and their performance impacts at the corporate level (e.g. Tanriverdi, 2006; Ravichandran et al., 2009; Tanriverdi and Uysal, 2011). For example, Tanriverdi (2006), based on a sample of 356 multi-business Fortune 1000 firms, demonstrates that super-additive value synergies can be created from the use of 
a complementary set of IT and management processes to have a significant impact on corporate performance. Another area where cross-business synergies can be created from integrating IT and IT management processes is in mergers and acquisitions (Tanriverdi and Uysal, 2011). However, in the multi-business context, research on IT-related synergies and their forms remains limited.

At the business level, several authors have also used synergies to refer only to the capabilities created from combining IT and another organisational factor within an organisation to understand IT's impact on organisational performance (e.g. Nevo and Wade, 2010; Roberts and Grover, 2012). Roberts and Grover (2012), for instance, show that "knowledge creating" synergy can be derived from the interrelation between a firm's web-based customer infrastructure and its analytical ability while "process enhancing" synergy can be obtained from the interrelation between a firm's coordination efforts and its level of information systems (IS) integration; these synergies in turn will impact the firm's competitive activity.

Similarly at the business level, though without explicitly using the term synergies, a large body of research has conceptualised and empirically examined IT business value based on pairwise alignment or complementarity between IT and strategy, IT and structure, IT and process, or IT and culture (Cao, 2010). A common theme emerging from these studies is that when IT and another organisational factor are aligned or complementary, together they improve organisational performance; when they are misaligned, organisational performance is negatively impacted.

\subsection{IT business value from the $R B V$}

To underpin research on IT business value, the RBV has been widely used to understand the origins of superior performance reflecting underlying efficiency differences across firms (Leiblein, 2011). While a firm's resources could be defined as tangible and intangible assets (Wernerfelt, 1984), resource heterogeneity, "one of the cornerstones of resource-based theory" (Helfat and Peteraf, 2003, p. 997), describes how a firm can capture more value than its rivals (Barney, 1991; Ambrosini and Bowman, 2009). From the RBV, IT can rarely be heterogeneous (Doherty and Terry, 2009); but when IT and another organisational factor are complementary, together they are because the joint use of assets is value enhancing (Teece, 2007) and synergistic (Eisenhardt and Martin, 2000). For example, heterogeneity and thus business value are seen to be created when IT combined with organisational strategy (Eisenhardt and Martin, 2000; Teece, 2007), with organisational processes (Ray et al., 2004), or with a firm's innate structural and/or cultural factors (Barney, 1991; Lado and Wilson, 1994; Miller, 2003). The RBV has provided a powerful explanation of how IT business value might be created from the joint effects between IT and another organisational factor. However, one of the main problems of the RBV is: "it concerns parts of strategies rather than wholes; and it embraces elements more than complementarities or relationships among those elements. As a result we are far from understanding what it takes for a company to effectively develop and implement a comprehensive strategy" (Miller, 1996, p. 508). Moreover, the appropriateness of using pairwise relationships as the basis to understand IT business value has been questioned and the need for a holistic approach is emphasised (e.g. Brynjolfsson and Hitt, 2000; Cao et al., 2011; Fink, 2011; Wiengarten et al., 2013). Fink (2011), for example, argues that these pairwise approaches are reductionist and only partly capture the complex forms of the interrelation to create IT business value. From a systems perspective, "they focus on parts of problem 
ITP

29,3

560

situations rather than the whole, they take little account of the interactions between parts" (Jackson, 2006, p. 647). All these call for a more holistic view to further advance understanding of IT-related synergies and IT business value at the systems level.

\subsection{Systems emergent properties and IT business value}

Systems perspectives encourage looking at organisations or other entities in terms of wholes that exhibit emergent properties or synergies, which are not present in the elements of a system (Ackoff, 1971; Churchman, 1971), or could not be fully explained by systems elements (Goldspink and Kay, 2010). The notion of emergent properties was sketched in the eighteenth and early nineteenth centuries (Ablowitz, 1939), which asserts that "the whole is more than the sum of its parts" based on two assumptions. The first is that there are different levels of existence: from the simpler (or lower level) elements to the more complex (or higher level) wholes that are composed of simpler elements and wholes. Second, new properties will be generated from the togetherness of or the relations between these elements, which are not deducible or predictable from the nature of the elements. Thus emergent property, which is essentially novel and non-additive, could be distinguished from "resultant" property, which is the additive combination that can be "foretold exhaustively from the individual elements" (Ablowitz, 1939). Similarly, Laszlo and Laszlo (1997, p. 9) suggest that "an emergent property is marked by the appearance of novel characteristics exhibited on the level of the whole ensemble, but not by the components in isolation. There are two important aspects of emergent properties: first, they are lost when the system breaks down to its components - the property of life, for example, does not inhere in organs once they are removed from the body. Second, when a component is removed from the whole, that component itself will lose its emergent properties - a hand, severed from the body, cannot write, nor can a severed eye see".

Thus, drawing on a systems perspective, there are fundamental issues related to understanding IT business value based on the synergies generated from pairwise relationships. A systems perspective suggests that IT business value is the behaviour of the system rather than that of the parts. It is the combined result from the interrelations among IT and other systems elements, which is not present in IT or other systems elements alone. Moreover, synergies generated from pairwise relationships are the behaviour of a part of the system rather than of the whole system. Thus, it is very unlikely and unconvincing that the behaviour of a system could be adequately analysed based on the effects of pairwise relationships.

\subsection{Human agents and their role in shaping systems emergent properties}

In addition, to understand emergent properties in the IT context, it is necessary to recognise the characteristics of emergent properties in organisational systems. Goldspink and Kay (2010) suggest that the range and type of emergent properties in an organisational system are affected by people, represented by different agents such as decision makers, within the system because they have the ability to distinguish "self" from "other", to change the rules of interrelations within the system, and thereby to reflexively interrelate with the systems environment. Furthermore, human agents cannot be expected to behave entirely rationally on economic grounds. For example, it is possible that a group of powerful people within a system tend to maintain power imbalances among different groups of people; the resultant emergent properties of the system can therefore be "good" or "bad" (Weetman, 2009). It follows that IT business 
value will depend on how the human agents of an organisation purposefully interrelate within the organisation and with its environment by, for example, developing business strategies that are supported by organisational structure, processes and culture, and enabled by various IT systems. Then the organisation's unique interrelations shaped by the decisions and knowledge of the human agents (Conner and Prahalad, 1996) will lead to distinctive emergent systems properties that in turn will affect how the organisation realises business value from its IT investment. This may explain why different firms in an industry have differential IT impacts on organisational performances (Conner and Prahalad, 1996; Brynjolfsson, 2003) as each firm is likely to have varied interrelations among its IT and other systems elements, affected by its unique managerial behaviour. Thus, emergent properties of a system tend to be system specific rather than generic.

\subsection{The dynamic nature of systems emergent properties}

Furthermore, from the open systems perspective (Von Bertalanffy, 1950), a system's emergent properties are dynamic instead of static, as the system assimilates inputs from its environment and is self-organising (Midgley, 2000). In order for the system to function effectively, it needs to adjust internal relationships between its elements to respond to the changing patterns of external environmental factors. Thus, the emergent properties of the system are likely to change over time: emergent property A of the system at time $T_{1}$ based on specific interrelations within the system and with its environment will change to emergent property $B$ at time $T_{2}$ when new patterns of systems interrelations are formed. Consequently, the system's emergent properties can be either relevant and valuable or obsolete to the system when the patterns of interrelations change over time; they are not a fixed constant but a dynamic function of the interrelations of the system. This suggests that unless the emergent properties of a system are developed and redeveloped over time by configuring and reconfiguring its subsystems to enable the system to effectively respond to the pressures from its environments, the system is doomed. The dynamic nature of systems' emergent properties and the importance of managing this dynamic feature cannot be overstated.

In summary, the literature review suggests that understanding IT business value by examining subsystems relationships is unable to capture and explain the complex nature of IT business value that is derived from systems' emergent properties. Systems concepts such as wholes and emergent properties are appealing; however, in order to understand IT business value holistically, significant conceptual advancement is required as no research has yet conceptualised IT business value at the organisational level based on a systems perspective.

\section{Theoretical development}

Having argued that IT business value is related to the complex nature of a system's interrelations between IT and other systems elements and with the systems environment, this section understands IT business value by introducing the new concept of systemic capabilities to emphasise the importance of the emergent properties of a whole system.

\subsection{The concept of systemic capabilities}

In this research, systemic capabilities are defined as the emergent systems abilities generated at the systems level from the synergistic interrelations between IT and other
IT business value 
ITP

29,3

562

systems elements within an organisation as a system. Systemic is used in the sense that an organisation is understood as a system composed of systems elements or subsystems, such as people, IT, strategy, structure, process and culture; and that the focus is the whole system and how the subsystems interrelate and are affected by purposeful human actions. The concept of capabilities is adopted from the dynamic capability view evolved from the RBV to generally refer to "the capability to sense opportunities, the capacity to seize opportunities, and the capacity to manage threats" (Augier and Teece, 2009, p. 412), such as customer-sensing capability and customerresponding capability (Roberts and Grover, 2012) and innovation capabilities (Lawson and Samson, 2001). It also refers to the ability of the system and especially the decision makers of the system to "purposefully create, extend or modify" (Helfat et al., 2007) or "integrate, build, and reconfigure" various subsystems' functions or competencies to respond to the pressures from the systems environment (Teece et al., 1997). Therefore, capabilities can refer to both processes and abilities (Ambrosini and Bowman, 2009), such as problem-defining and problem-solving routines (Bitar and Hafsi, 2007). Such capabilities are the likely sources of superior business value; however, they do not necessarily translate into actualised business value (Bitar and Hafsi, 2007; Ambrosini and Bowman, 2009).

To understand systemic capabilities, the human agents, decision makers in particular, within a system must be placed at the centre of the discussion as they play a significant role in shaping the systems interrelations by purposely (re)configuring its subsystems with the changing business environment. Since decision makers vary in their ability to manage the complex interrelations, depending on their motivation, skills, and experiences (Zahra et al., 2006); different systems are likely to have different systemic capabilities and therefore different performances (Leiblein, 2011). It can be expected strong systemic capabilities will be developed when a system's decision makers are able to accurately sense changes and opportunities in environmental factors such as technology, customer and competition, and are able to make effective decisions and develop well-conceived strategies, enabling processes to allow IT and other elements within the system to work together synergistically.

In summary, systemic capabilities are:

- emergent properties generated from synergistic interrelations among a system's elements;

- novel features exhibited only at the level of the whole system but not by the elements in isolation; and

- dynamic rather than static, affected by unique human behaviour and how the system interrelates internally and externally with its environment.

Furthermore, this paper's view of IT business value based on the concept of systemic capabilities appears to resemble one seminal research on IT business value conducted by Wade and Hulland (2004). Based on the RBV in general and resource complementarities in particular, they focused on the relationship between IS resources (interchangeably IT in this paper) and competitive positions and performance. They examined the potential impact of key IS resources in terms of six resource attributes and developed eight sets of propositions. Of particular relevance to this paper, they highlighted the moderating effects of organisational factors (such as top management commitment to IS, organisational structure, and corporate culture) and environmental factors in creating IT business value. While this research also 
recognises the importance of organisational and environmental factors and emphasises the role of human agents, including but not limited to key decision makers, in creating IT business value, this research focuses on systems interrelationships and the resultant

systemic capabilities; this moves away from resource complementarities or pairwise relationships. While organisational and environmental factors are likely to moderate how IT creates business value, the concept of systemic capabilities could be used to conceptualise other conceivable possibilities at the systems level, which could be explored in future research. Thus:

P1. The more the systems elements work together synergistically, the stronger the systemic capabilities become.

\subsection{Examples of systemic capabilities as emergent systems properties}

Having discussed the concept and the key properties of systemic capabilities, next several examples follow to further explain why systemic capabilities are higher order or more complex competencies at the systems level that cannot be produced or predicted by the behaviour of IT and other systems elements taken separately (Corning, 2002).

When IT and other systems elements interrelate, they are likely to become "an integral part of all organizing" that is inextricably fused, inherently inseparable, and interpenetrating (Orlikowski, 2007; Zammuto et al., 2007; Orlikowski and Scott, 2008). The resultant systemic capabilities will then turn into assemblages that are not susceptible to being reduced to properties that can be derived from subsystems such as pairwise relationships. However, systemic capabilities may exist in many different forms depending on one's perspective and how the interrelations among systems elements are managed.

For example, from the perspective of the value chain model (Porter and Millar, 1985), it is likely that a company may develop systemic capabilities in the areas of logistic, operations, marketing and sales, service, firm infrastructure, human resource management, technology development and procurement. Based on the idea of balanced scorecard (Kaplan and Norton, 1992), alternatively, systemic capabilities can be understood in terms of financial perspective, internal business process, customer perspective and innovation and learning perspective. Additionally, these systemic capabilities may also be manifested in the forms of "the capability to sense opportunities, the capacity to seize opportunities, and the capacity to manage threats" (Augier and Teece, 2009, p. 412) in various organisational areas. Thus, the concept of systemic capabilities can be applied to any organisational areas to understand the emergent properties resulting from the wholes or the synergistic interrelations among systems elements, which may or may not include IT; though it is inconceivable that any modern business organisations can function properly without using IT as one important organisational factor.

Specific systemic capabilities could be exemplified by analytic capabilities that are rapidly gaining in importance and focus, as organisations address the challenges of meeting increasingly demanding customer expectations, processing big data that is "high volume, high velocity, and/or high variety" (Watson, 2014), and staying one step ahead of the competition. In order for organisations to develop analytic capabilities, IT, business strategy, understanding of customers, a data-driven culture, and organisational processes must be "closely linked" and infused into each other (Lavalle et al., 2011). Another example is innovation capability, which is argued to be 
ITP

29,3

564

developed from the integrative result of a system of seven interdependent elements, namely vision and strategy, harnessing the competence base, organisational intelligence, creativity and idea management, organisational structures and systems, culture and climate, and management of technology (Lawson and Samson, 2001). Other examples of systemic capabilities may include Wal-Mart's capabilities generated from mutual reinforcement among its IT and organisational factors (Brynjolfsson, 2003), and Dell's excellent value chain capability, which is the combined result of the interrelations among its virtual integration enabled by the internet, strategies of built-to-order and direct sales, customer focus, supplier partnerships, mass customisation, and just-in-time manufacturing (Magretta, 1998). The impact of these systemic capabilities can only be adequately understood at the systems level through examining the interrelations among IT and various systems elements: any attempt to understand those systemic capabilities and/or their performance impact based on subsystems relationships is necessarily limited at best and misleading at worst.

\subsection{IT business value from the perspective of systemic capabilities}

Having defined and explained the concept of systemic capabilities, an organisation's IT business value can now be defined as the organisational level performance impacts (Mukhopadhyay et al., 1995; Melville et al., 2004) of systemic capabilities. When a system's IT and other systems elements work together to the utmost extent, superb systemic capabilities will be generated to greatly improve the system's IT business value.

From the RBV, systemic capabilities of a system can be heterogeneous, thereby to become the source of sustained improvement in performance. If the joint use of assets is already value enhancing (Teece, 2007) and synergistic (Eisenhardt and Martin, 2000), a system's systemic capabilities generated from the subsystems working together are more likely to maximally enable the system to create synergies at the systems level and to realise its IT business value. It can be expected that when a system has well-conceived value-creating business strategies, which are supported by effective business processes and structure, facilitated by reinforcing organisational culture, and enabled by IT, the system can be expected not only to purposefully minimise conflict of interests, frictions, problems, or costs, but more importantly to integrate various subsystems' functions or competencies to create novel systemic capabilities to sense and seize opportunities and to manage threats. However, systemic capabilities are almost certain to be rare since not many organisations may have the ability to develop such capabilities. Nolan and Mcfarlan (2005, p. 96) assert that most firms even "remain largely in the dark when it comes to IT spending and strategy"; then arguably they would be most unlikely to have managed the interrelations among IT and other systems elements to develop systemic capabilities. Similarly, Lim et al. (2011) suggest that only a subset of firms has been actively developing IT capabilities and they are more likely to repeat this than firms lacking such experience. Building upon these ideas, it can be argued that an even smaller subset of firms is likely to develop and redevelop systemic capabilities since it is extremely difficult to manage a firm's subsystems in ways they can interrelate synergistically. Prior studies suggest that IT combined with a firm's innate structural and/or cultural factors is socially complex and thus difficult to duplicate (e.g. Bharadwaj, 2000; Miller, 2003; Ray et al., 2004; Teece, 2007); that IT capability is path dependent on prior choices and experiences (Piccoli and Ives, 2005; Lim et al., 2011) and thus is comparatively more inimitable (Bhatt and Grover, 2005); and that unique organisational capabilities created from the interdependence among various organisational factors are impossible to copy 
because the interrelationship is so complex and ambiguous (Miller, 1996). Along these lines, it can certainly be argued that systemic capabilities are even more heterogeneous since they are the combined results of the distinctive interrelations among a firm's unique business strategy, structure, process, culture, and IT, which are further compounded by reflexive human actions and unique managerial know-how (Peteraf, 1993; Conner and Prahalad, 1996) and the process and interconnectedness of capability development (Dierickx and Cool, 1989). For reasons outlined above, systemic capabilities are seen to be idiosyncratic to a firm.

Furthermore, in order for IT to be a source of sustained improvement in performance, Wade and Hulland (2004), based on prior RBV research, identify two more conditions to be met: appropriability and imperfect mobility. The former refers to who will capture the value that the resource creates; the latter refers to the extent to which the resources can be obtained by competing firms. It can be argued that systemic capabilities will be appropriable in the long term rather than in the short term because systemic capabilities are organisationally complex to develop, taking time to ensure that all key systems elements work together. However, once a firm has developed systemic capabilities, they should allow the firm to significantly improve its effectiveness. It can also be argued that systemic capabilities are perfectly immobile (Peteraf, 1993) since they are system specific rather than generic: they are generated from the distinctive interrelations among a firm's IT, unique business strategy, structure, process and culture, and unique human behaviour.

To recap, the above discussion suggests that systemic capabilities tend to be heterogeneous; consequently, it may be postulated that the more an organisation develops and redevelops its systemic capabilities, the more likely it is to realise superior business value from its investment in IT for sustainable improvement in performance. Thus:

P2. Strong systemic capabilities will have a positive effect on an organisation's ability to leverage its IT business value.

Considering the complex nature of systemic capabilities and the uniqueness of every organisational context and the behaviour of the human agents, no simple prescriptions as how an organisation should (re)develop systemic capabilities for creating IT business value can be offered. However, unless organisations take steps to focus on creating synergistic emergent properties at the systems level, it is unlikely that they will be able to develop strong systemic capabilities to realise superior IT business value. Building on the research conducted by Lim et al. (2011) regarding developing IT capabilities, it can be similarly expected that organisations that have been actively developing systemic capabilities are more likely to be successful than those that lack such experience in creating business value from their IT investment.

\section{An example of leveraging IT business value through developing systemic capabilities}

To support this paper's argument and further illustrate the concept of systemic capabilities as a source of IT business value, an IT project participated in by the authors in a UK university is used to demonstrate and explain the complexity of how IT interrelates with organisational factors to create synergy and leverage IT business value. This example is also used to provisionally test the proposed research propositions. 
ITP

29,3

566

\subsection{Background information}

The example presented is about using emerging IT in a UK university (BS as its anonymous name) to track and manage student engagement. The project was concerned with the organisation-wide development and deployment of an intelligent student engagement system (SES).

As IT forms an essential and integral part of modern organisations, BS has been seeking to use IT to achieve its strategic goals and deliver its core services. To enhance student experience and manage student engagement in their academic study more effectively and efficiently, BS valued the role of IT and decided to look at better ways of managing student engagement using innovative IT. It was hoped that the use of IT would support BS's key initiative of identifying students at risks of disengagement or drop out who might need more help and support through their studies to ensure they fulfil their academic goals and enhance their experience. Thus, BS commissioned a project to produce a system which would provide data-driven insights into crossfunctional analysis and effective student engagement. Working with an industry leader in the fields of business intelligence (BI) and data warehousing, BS came up with a SES. Data input came from a number of online and offline sources. Fixed digital tracking devices were positioned in lecture theatres and seminar rooms across the university campuses to collect student engagement information. This information was then communicated back to a central database within BS. Users could access student tracking data via a SES dashboard.

However, the initial SES developed through the commissioned project had many limitations at the time it was implemented. Consequently, it was further improved with the support of two Jisc grants and additional internal funds two years after its implementation.

From a systems perspective, BS's SES is an important part of the whole BS-as-a-system consisting of the following elements:

- IT - this is related to all IT systems used or to be used. In the context of SES, technologies include RFID devices, Oracle database, data warehousing, Oracle BI platform, bespoke BI tools, etc. Student tracking data are from almost all areas of student learning activities.

- People - this involves all human agents, their roles and the ways that they interact, and the impact of their behaviour. A systems analysis of stakeholders showed that a very diverse group of people are involved as direct and indirect SES users or participants, including senior managers, faculty managers, academic staff, student engagement managers, students.

- Process - this is related to the processes involved in student management in general and student engagement management in particular. SES aims to facilitate and support a student engagement management process which was complex and dynamic in nature.

- Strategy - this includes BS's overall strategy for student experience and IT strategy, including the specific strategies for the student engagement management systems.

- Structure - this is related to BS's management structure in general and student management structure in particular. The system's structure affects the SES governance structure, thus would have significant impact on the system's value. 
- Culture - this refers to the organisational culture and how it supports and facilitates the delivery of overall organisation mission and goals. Culture can be an enabler or barrier to the development of systemic capabilities. In the context of SES, this paper's focus is to what extent student management decisions are made based on data-driven insights gained from the system.

Considering that SES is an integral part of the whole of BS, it is expected that effective student management in BS depends on the emergent properties resulting from the interrelation between all key systems elements of BS rather than that of SES in isolation. Before demonstrating whether SES interrelates with organisational factors creates synergy and IT business value, the research methods used to improve the initial SES is described next.

\subsection{Research methods}

An action research approach was used, which was an iterative process involving researchers and practitioners acting together on a particular cycle of activities, including problem diagnosis, action intervention, and reflective learning (Avison $e$ t al., 1999). The action research aimed to deliver an improved SES with the support provided by two Jisc grants and BS internal funds. Two of the authors were the key actors in the action research. One was the project leader aiming to improve the initial SES and was mainly responsible for developing an improved SES with BI dashboard; another was the project investigator and mainly responsible for evaluating the impact of the improved SES from a systems perspective.

Problem diagnosis - identifying problems of the initial SES. Equipped with a systems perspective, the main aim of the diagnosis was to have a comprehensive understanding of BS as a system and identify the problems with the initial SES developed about two years ago with an intention to improve its business value. A university-wide survey (50 responses), one focus group with staff, one management think tank meeting, and six interviews were carried out with various stakeholders of the SES project.

Action intervention - developing the improved SES. During this phase, the project team worked closely with internal and external key stakeholders to develop interventions to improve the initial SES. Based on the evidence of the various empirical data collected in phase one, users and potential users of SES had highlighted three essential requirements for improving the initial SES with BI solutions. Working in partnership with the external IT supplier and other key stakeholders, such as registry, faculty managers, student service, internal ICT service, BI researchers, and academics, the initial SES was improved to have dashboard with BI tools, such as: flexible student engagement measurement index, interactive and personalised dashboard for engagement reporting, and automatic risk alert system.

Reflective learning - evaluating the improved SES. This phase aimed to understand the impact of the improved SES and critical issues surrounding the successful SES development and deployment in the organisation from a systems perspective. As the action research was underpinned by the systems perspective, the reflective learning was focused on the identification of systemic capabilities and the subsequent IT business value. This phase involved eight interviews with senior and middle managers, a SES user survey (20 responses), one focus group with students, two user observations, three SES business action group meetings, and secondary data analysis of internal documents, meeting notes, verbal and electronic communications with key stakeholders. 
ITP

29,3

568

Both qualitative and quantitative data were collected during the action research process. The quantitative data were analysed using SPSS to provide an overview of the initial SES usage and limitations (first survey) and the perceived benefits of the improved SES (second survey). Qualitative data collected from interviews, focus groups, and internal meeting notes and documents were analysed using content analysis approach to generate key themes and subthemes that helped improve the SES's functionalities and provided the evidence on the initial impact of the improved SES. The key findings from the action research are summarised as follows to test the research propositions.

\subsection{Testing the research propositions}

The two research propositions developed in Section 3 will be tested in two stages. First, the findings from the initial SES will show that limited systemic capabilities and thus little IT business value were developed from BS when the system's elements did not work together as a whole. Second, the findings from the improved SES will provide evidence to demonstrate that stronger systemic capabilities and therefore greater IT business value can be developed from BS when the system's elements work together synergistically.

Initial SES with limited systemic capabilities and business value. The initial SES went live a few years ago; however, "it served merely as an information source for limited number of users, rather than a decision support environment for achieving transformational changes and enhancing student experience" (quote from BS Jisc project proposal). Based on the evidence of various investigations and assessments undertaken during the problem diagnosis phase (see Section 4.2), it was clear that the initial SES was still in its infancy in terms of realising its full potential as a data source to support evidence-based decision making and strategic planning. One key reason indicated by the investigations was that the system elements discussed in Section 4.1 tended to work in isolation and there was little mutual reinforcement among the systems elements. For example, the system was not known and used by most of its potential users; there was no university-wide recognition and awareness of the initial SES (an SES survey showed that 62 per cent of respondents were not aware of it); the system was developed following an IT-driven approach because "BS IT experts and the external supplier worked collaboratively and produced a workable SES” (BS internal report). As a result, the initial SES was mainly seen and used as a data collecting system for the UK government's student visa compliance regime, while student engagement management was little affected by the initial SES. Besides, there was no organisation-wide IT strategy, IT governance structure, nor associated processes especially developed to leverage the data-driven opportunities provided by the initial SES to improve BS student engagement management.

As a result, the initial SES tended to be a standalone element rather than closely interrelated with other key systems elements. Thus, few, if any, student-engagementmanagement-related emergent properties resulted from BS as a whole system, and very limited business value was created from the initial SES itself as it was considered only as a basic system to collect and record data. Even as an IT system, it "suffered a number of problems and limitations in many critical areas", such as "limited value for higher level support", "poor usability", "speed of system (lack)", "integration with other student data sources", "no method of recording high engagement (to the student achievements)", "checking data quality" (management think tank meeting notes), and 
needed significant improvement. Arguably, these problems could have been significantly mitigated if a systems perspective had been used to design and develop the system so the interrelationship between the initial SES and other key elements of BS such as users and decision-making processes of BS student engagement management could have been better coordinated.

In summary, the investigations in the problem diagnosis phase undertaken two years after the initial SES implementation indicated that the systems elements did not work together as a whole regarding how student engagement could be managed; thus limited, if any, systemic capabilities in student management were developed; and consequently, limited business value from the initial SES was realised. As argued by Laszlo and Laszlo (1997), the emergent properties, i.e. systemic capabilities that could have resulted from the element working synergistically would be "lost when the system breaks down to its components".

Therefore, this paper's analysis of the initial SES implementation provides evidence to support $P 1$ and $P 2$ by demonstrating that limited, if any, systemic capabilities could be developed from a system if the system's elements do not work together synergistically; and that limited systemic capabilities constrain an organisation's ability to leverage its IT business value.

Next, the findings from the improved SES will be used to reveal if stronger systemic capabilities and therefore greater IT business value could be developed from a system when the system's elements work together as a whole.

Improved SES with stronger systemic capabilities and business value. Although the initial SES had limited business value, the university-wide investigation indicated that there was a general consensus that SES was potentially very valuable in providing important information in support of BS's strategy and policies (BS Jisc project report). With the appointment of a new senior manager (registrar), the BS senior management team started to realise the potential SES strategic value and the importance of aligning the system with BS's student engagement policies and objectives. After a careful review of potential SES applications, it was clear at that time that the potential strategic, operational, and transformational value (SES internal report) of the system for the institution would be great, although the realisation of the system's value was considered a significant challenge (BS Jisc report). Nevertheless, BS wanted to improve the existing system further and decided to provide appropriate human and financial resources for the project two years after the initial SES's implementation. As part of the effort to improve the SES and realise its strategic value, the project team, including the authors as key members, also applied and received two Jisc grants. These grants supported one of the key principles advocated by Jisc, a holistic approach to realise the strategic value of IT. For example, Jisc's Transformations programme was "aimed at supporting institutional staff across 57 university project's to effect large-scale organisational change, underpinned by ICT, where there is an objective to enhance student experience, improve operational efficiency, and enhance organisational capability for business and community engagement" (Jisc, 2013, emphsis added). Jisc stressed the need for "understanding the HEI as a holistic entity" and considering "its structure, products, operations, technology, and the web of relations tying these together" (Dhugga and Addison, 2011, p. 50).

As a result, the project team adopted a holistic approach to improving SES for better student management. The project activities consisted of many interrelated activities through the action research process including identifying problems, developing 
ITP

29,3

inventions, and evaluating initial impacts. Of particular relevance to the current research is how a holistic approach to improving SES was conducted in ways that the interrelatedness and mutual reinforcement among the BS elements had been emphasised throughout the action research process.

For example, during the invention development process, the project team worked closely with internal and external key stakeholders to develop interventions. Understanding the SES holistically, the project team was not just looking for technological interventions, but for the interrelatedness of all key systems elements working as whole in achieving the project objectives, which was one of the key lessons learnt from the initial SES implementation. Thus, in the process of improving the SES, the mutual reinforcement among systems elements was strongly emphasised this time. The project team worked in partnership with the external IT supplier and other key stakeholders, such as the registry, faculty managers, student services, IT service, BI researchers, academics, and students. In addition to human agents working together, the other system elements, IT, strategy, structure, process, and culture, were purposefully shaped or developed by the human agents so they could support each other. For example, the new senior manager (university registrar) set up clear IT strategy and governance structure at the top management level; a think tank session helped to understand the SES improvement requirements and business value; a business action group consisting of all key stakeholders was formed and met regularly during the SES improvement stage; many interviews, a number of surveys and focus groups were carried out to encourage dialogue, communication, and understanding.

The purposefully nurtured interrelatedness of all system elements resulted in clearly discernible emergent systems properties in the area of student engagement management. For example, BS developed a new IT strategy and "there is a real sense of energy and momentum gathering behind the ICT strategy. This will facilitate marked progress and change to deliver a real transformation in the quality of the IT services provided across the university" (quote from BS senior management group meeting minutes). The highlight of the new IT strategy included new IT governance and support for and improvements to student experience (BS internal document from ICT director). The SES management and governance structure were clarified with clearly assigned responsibilities, timetables, and system ownerships. The new IT strategy, new BI strategy, management structure, and stakeholders' closer interactions fostered a stronger sense of data-driven culture in the organisation which resulted in a better use of the insights derived from the SES to improve the student engagement management.

Consequently, stronger capabilities in student engagement management were generated at the organisational level, which are reflected in the following areas:

- The capability to support individual student engagement managers and tutors with real-time and holistic data, so they can make fact-based decisions for effective interventions and be more proactive in taking actions. For example, "Student engagement team can now identify student at risk and set meetings with Personal Tutors, which was not previously possible" (BS Jisc case study report).

- The capability to support BS as an organisation in managing students at risk of disengagement or drop out. For example, "managing a diverse range of over 20,000 students during their academic life in the university has always been a 
challenge as well as a threat because of the government's tough policy on funding and immigration control" (interview of a senior manager). BS has to improve its student retention rate as well as collecting data about international student engagement status. Otherwise, BS might lose its status for recruiting international students and funding if students disengage or drop out. As indicated in BS's two Jisc project reports, SES (IT element) was significantly improved, new IT strategies and management structures were launched, and a new student engagement management team was created with clearer responsibilities and improved tracking and reporting processes. Most importantly, a data-driven culture was gradually created to encourage fact-based decisions using insights generated by SES data.

- The capability to "integrate, build, and reconfigure" various subsystems "student engagement systems cannot be developed and deployed in isolation" (interview of SES project manager). It affected other BS subsystems ranging from people, process, strategy, and structure. BS was able to have a successful SES in place through integrating various subsystems involving IT systems, management processes, management structure, governance, and student management strategy. These capabilities are the result of a much improved SES that has "become an integral part of BS's overall student engagement management system" (interview of SES project manager) and contribute to "a more efficient and effective student management and better student experience" (interview of a senior manager).

As discussed in Section 3.1, it can be argued that these capabilities are emergent properties generated from the synergistic interrelations among the systems elements and exhibited only at the level of the whole system but not by the elements in isolation. They are also dynamic rather than static affected by the continuing synergistic interactions among the system's elements because new or stronger capabilities will be re-generated as long as the systems elements continuously work together as a whole. For example, BS senior student service managers are still actively seeking new solutions to further improve the system and associated processes; the SES users are also proactively involved in providing feedback. All the system's elements are constantly working together to strengthen the systemic capabilities. The SES is reviewed and subject to further significant improvement in terms of adding new data dimensions and learning analytics tools. For example, BS's IT director and student service director have recently (June 2015) invited a leading IT supplier to demonstrate how to use new Wi-Fi and mobile tracking technology to develop spatial intelligence for student engagement tracking on campus. This indicates that having better realised the business value of the SES, BS now intends to repeat this practice, which is consistent with the view that organisations that have been actively developing IT capabilities are more likely to repeat this practice (Lim et al., 2011).

Therefore, this paper's analysis of evidence collected in the improved SES again has provided evidence to support $P 1$ : the more the system's elements work together synergistically, the stronger the systemic capabilities become.

To identify the initial impact and value of the improved SES, eight interviews were conducted from which the evidence suggested that BS had realised better business value was in its investment in the improved SES. Various investigations conducted in the action research's reflective learning phase demonstrated the business value of the 
ITP

29,3

improved SES was due to the strong synergies and dynamic interrelations in the organisation. This was evidenced in action items identified by the SES business action group, eight interviews with senior and middle managers, case study reports and videos for the funding body, Jisc, minutes of meetings and verbal and electronic communications among all stakeholders. The key business value of the improved SES includes (BS Jisc case study report):

- Significantly increased the number and diversity of the SES users, and created a new student engagement management team supported by SES. For example, "the number of the SES direct users has increased from 6 users at the start of the project to 100 active users now" (BS Jisc case study report).

- Improved effectiveness and efficiency in identifying students at risk at an early stage, thereby taking more proactive approaches to improving student retention and positively changing student engagement behaviour.

- Improved communications, increased SES value, and improved organisational efficiency.

- Increased institutional awareness of IT governance in providing the management framework for harmonising institutional strategy and structures with performance goals, measures, and accountabilities.

- Improved knowledge and understanding of the importance and necessity of strategic alignment and harmony between IT, people, strategy, structure, process, and culture.

- Improved knowledge and understanding of systems integration enabling greater sharing of knowledge and resources across the organisation.

Therefore, this paper's analysis of evidence collected in the improved SES again has provided evidence to support $P 2$ : strong systemic capabilities will have a positive effect on an organisation's ability to leverage its IT business value.

\section{Discussion and conclusions}

Research suggests that while IT has become an important and integral part of most organisations, IT-related "troubles" are still widespread. Explanations of how IT might create business value are thus fundamental issues central to IT business value researchers. In this context, although substantial research effort has gone into examining the impact of IT on organisational performance, pairwise relationships between IT and other organisational factors are typically conceived and examined; there seems to have been little theorising at the level of a whole organisation to understand the emergent properties resulting from the interrelationships among IT and other organisational factors. This research drew on a systems perspective and studied how IT creates business value by introducing the concept of systemic capabilities and developing a systemic conceptual framework for IT business value, tentatively supported by an example. The research helps to move away from pairwise relationships to focusing on the whole system.

With respect to how IT creates business value, this research suggests that the emergent properties resulting from the interrelations among IT and other organisational elements at the systems level are essential to explicating whether sustained improvement in performance could be gained. The results 
demonstrate that IT business value can be created by developing systemic capabilities that are generated from IT working synergistically with other systems elements. Such systemic capabilities are novel emergent properties exhibited only at the level of the whole system, and are not susceptible to being reduced to properties that can be derived from subsystems. They are dynamic as they are affected by how the system interrelates internally and externally with its environment. Furthermore, systemic capabilities of different systems are likely to be idiosyncratic because the human agents within a system are likely to vary in their motivation, experiences, and ability to manage the complex interrelations within the system and with the systems environments. Overall, this paper has stressed the significance of the need for understanding IT business value systemically and dynamically, and thus contributed mainly to the literature on IT business value.

\subsection{Theoretical contributions}

Extant literature on IT business value has thus far dominantly focused on pairwise relationships to understand how IT creates business value (Cao, 2010). However, pairwise relationships have limited descriptive capacity and weak explanatory power because they reduce complex systems interrelations into subsystems behaviours, which are unable to capture and explain emergent systems properties. Consequently, a few articles have called for understanding IT business value more holistically (e.g. Brynjolfsson and Hitt, 2000; Cao et al., 2011; Wiengarten et al., 2013). Responding to this call, this paper makes several contributions to the literature.

First, departing from using pairwise relationships, the paper has developed the concept of systemic capabilities and a systemic conceptual framework to highlight that IT creates business value based on its interrelation with other systems elements to generate novel emergent systems properties that are not present in subsystems alone. That is, systemic capabilities only exhibit at the systems level, which will positively affect IT business value. Additionally, the paper emphasises that an organisation's IT business value will depend on how people within the organisation purposefully shape the interrelations within the organisation and with its environment by (re)configuring organisational elements. These people and environmental elements reveal that systemic capabilities are dynamic rather than static. This conceptual understanding of IT business value offers richer descriptive content and has stronger explanatory capacity and predictive power. These findings will, hopefully, inspire others to conduct further systemic research so that a comprehensive understanding of IT business value may be developed.

Second, this paper contributes to the RBV by moving away from the concept of pairwise resource complementarity to focusing on the synergistic interrelations among multiple systems elements. When synergy is understood at the pairwise resource level, its link to sustained improvement in performance can be problematic (Miller, 1996; Fink, 2011) because the behaviour of subsystems cannot be used to predict the system's behaviour. This study has demonstrated that when IT works synergistically with other systems elements, together they will create novel systemic capabilities that will enhance IT business value. Another contribution to the RBV is that the concept of systemic capabilities is seen to be generally applicable to other business and management areas rather than limited to IT business value; thus it offers an alternative perspective to help understand the relationship between various organisational capabilities and their impact on organisational performance. 
ITP

29,3

574

Third, this research also contributes to systems literature by generating support for understanding IT business value informed by a systems perspective to "help managers address complex problem situations" (Jackson, 2006). It demonstrates that a systems perspective provides a valuable conceptual lens through which IT business value as the emergent property resulting from synergistic systems interrelations can be better understood; thus the need to understand IT business value systemically will not be overlooked. This not only provides support for but also is consistent with the literature (e.g. Brynjolfsson and Hitt, 2000; Cao et al., 2011; Fink, 2011; Wiengarten et al., 2013). Further, this paper has also extended systems concepts. The notion of emergent properties in systems literature is appealing but also difficult to apply (Jackson, 2006) as systems concepts are often not defined explicitly (Mulej, 2007) or "the practical relevance of the systems approach" has remained vague and limited (Ulrich, 1993). This paper helps demystify emergent systems properties through clearly defining the concept of systemic capabilities and providing explicit examples of systemic capabilities to illustrate the usefulness and applicability of systemic capabilities to organisations.

\subsection{Implications for practice}

This study has several important implications for practice. First, organisations making important IT investment decisions should focus on (re)developing systemic capabilities at the systems level by ensuring that IT and other organisational elements work together as a synergistic whole. If important IT applications are implemented based on understandings of pairwise relationships such as aligning IT with business strategy, which is necessary but incomplete and insufficient, they are likely to concentrate on subsystem behaviours and thus may miss opportunities to create higher order systems competencies that cannot be produced at the subsystems level. Second, an organisation investing heavily in IT should better manage the role that various human agents play in developing systemic capabilities, as their behaviour and knowledge will uniquely shape the interrelations among IT and other systems elements (Conner and Prahalad, 1996), which leads to idiosyncratic capabilities thereby affecting its performance. The final implication for practice is that an organisation should develop and redevelop its systemic capabilities over time by purposefully (re)configuring its IT and other resources to effectively respond to internal and environmental changes. Due to the systemic and dynamic nature of systemic capabilities and the uniqueness of every organisational context and human behaviour, there are no simple solutions for how to realise business value from IT investment. However, unless organisations take steps to develop their systemic capabilities, it is unlikely they can enhance their IT business value. The systemic framework proposed in this paper can, hopefully, help organisations delineate relevant IT investment considerations and the priorities they must adopt to realise superior business value from their IT investments.

\subsection{Limitations and future research}

This study is mainly conceptual in nature, although it has illustrated the key concepts and tentatively tested the research propositions with an example in a UK higher education institution in the IT context. Therefore, future research is required. First, more comprehensive or context-specific hypotheses can be developed based on the systemic framework to understand IT business value. Second, rigorous qualitative approaches such as case studies, interviews, and longitudinal studies could be 
employed to validate the research propositions and enrich our understanding of how an organisation can harness synergies created from integrating organisational subsystems to gain sustainable improvement in its performance.

Furthermore, the concept of systemic capabilities developed in this paper is seen to be generally applicable to other business and management areas, offering an alternative perspective to understand the association between organisational capabilities and performance. Thus, the exploration of different types of systemic capabilities, factors contributing to the development of systems capabilities, and how they develop and change over time in business and management offer an interesting and important direction for future research.

\section{References}

Ablowitz, R. (1939), “The theory of emergence”, Philosophy of Science, Vol. 6 No. 1, pp. 1-16.

Ackoff, R.L. (1971), "Towards a system of systems concepts", Management Science, Vol. 17 No. 11, pp. 661-671.

Ackoff, R.L. (1981), Creating the Corporate Future, Wiley, Place, Chichester.

Ambrosini, V. and Bowman, C. (2009), "What are dynamic capabilities and are they a useful construct in strategic management?", International Journal of Management Reviews, Vol. 11 No. 1, pp. 29-49.

Andersen, T. and Segars, A. (2001), "The impact of IT on decision structure and firm performance: evidence from the textile and apparel industry", Information \& Management, Vol. 39 No. 2, pp. 85-100.

Augier, M. and Teece, D.J. (2009), "Dynamic capabilities and the role of managers in business strategy and economic performance”, Organization Science, Vol. 20 No. 2, pp. 410-421.

Avison, D., Lau, F., Myers, M. and Nielsen, P.A. (1999), “Action research”, Communications of the ACM, Vol. 42 No. 1, pp. 94-97.

Barney, J. (1991), "Firm resources and sustained competitive advantage", Journal of Management, Vol. 17 No. 1, pp. 99-120.

Bharadwaj, A.S. (2000), "A resource-based perspective on information technology capability and firm performance: an empirical investigation”, MIS Quarterlv, Vol. 24 No. 1, pp. 169-196.

Bhatt, G.D. and Grover, V. (2005), "Types of information technology capabilities and their role in competitive advantage: an empirical study", Journal of Management Information Sustems, Vol. 22 No. 2, pp. 253-277.

Bitar, J. and Hafsi, T. (2007), "Strategizing through the capability lens: sources and outcomes of integration”, Management Decision, Vol. 45 No. 3, pp. 403-419.

Bradley, R.V., Pridmore, J.L. and Byrd, T.A. (2006), "Information systems success in the context of different corporate cultural types: an empirical investigation”, Iournal of Management Information Systems, Vol. 23 No. 2, pp. 267-294.

Brynjolfsson, E. (2003), “The IT productivity gap”, Optimize, Vol. 21, pp. 26-43.

Brynjolfsson, E. and Hitt, L.M. (2000), "Beyond computation: information technology", Organizational Transformation and Business Performance, Vol. 14 No. 4, pp. 23-48.

Cao, G. (2010), "A four dimensional view of IT business value”, Systems Research and Behavioral Science, (formerly Systems Research), Vol. 27 No. 3, pp. 267-284.

Cao, G., Wiengarten, F. and Humphreys, P. (2011), "Towards a contingency resource-based view of IT business value", Svstemic Practice and Action Research, Vol. 24 No. 1, pp. 85-106.

Cha, H.S., Pingry, D.E. and Thatcher, M.E. (2009), "What determines IT spending priorities?", Communications of the ACM, Vol. 52 No. 8, pp. 105-110. 
ITP

29,3

Churchman, C. (1971), The Design of Inquiring Systems: Basic Concepts of Systems and Organizations, Basic Books, Place, New York, NY.

Clegg, C., Axtell, C., Damodaran, L., Farbey, B., Hull, R., Lloyd-Jones, R., Nicholls, J., Sell, R. and Tomlinson, C. (1997), "Information technology: a study of performance and the role of human and organizational factors", Ergonomics, Vol. 40 No. 9, pp. 851-871.

Conner, K.R. and Prahalad, C.K. (1996), "A resource-based theory of the firm: knowledge versus opportunism”, Organization Science, Vol. 7 No. 5, pp. 477-501.

Corning, P. (2002), "Devolution as an opportunity to test the synergism hypothesis and a cybernetic theory of political systems", Systems Research and Behavioral Science. (formerly Systems Research), Vol. 19 No. 1, pp. 3-26.

Dhugga, P. and Addison, A. (2011), "Strategic ICT Toolkit", available at: www.nottingham.ac.uk/ gradschool/sict/ (accessed 28 July 2015).

Dierickx, I. and Cool, K. (1989), "Asset stock accumulation and sustainability of competitive advantage”, Management Science, Vol. 35 No. 12, pp. 1504-1511.

Doherty, N.F. and Terry, M. (2009), "The role of IS capabilities in delivering sustainable improvements to competitive positioning", The Iournal of Strategic Information Sustems, Vol. 18 No. 2, pp. 100-116.

Doherty, N.F., Champion, D. and Wang, L. (2010), "An holistic approach to understanding the changing nature of organisational structure", Information Technology \& People, Vol. 23 No. 2, pp. 116-135.

Drnevich, P.L. and Croson, D.C. (2013), "Information technology and business-level strategy: toward an integrated theoretical perspective”, MIS Quarterlv, Vol. 37 No. 2, pp. 483-509.

Dutta, A., Lee, H. and Yasai-Ardekani, M. (2014), "Digital systems and competitive responsiveness: the dynamics of IT business value", Information \& Management, Vol. 51 No. 6, pp. $762-773$.

Eisenhardt, K.M. and Martin, J.A. (2000), "Dynamic capabilities: what are they?”, Strategic Management Journal, Vol. 21 Nos 10-11, pp. 1105-1121.

Farbey, B., Targett, D. and Land, F. (1994), "Matching an IT project with an appropriate method of evaluation: a research note on 'evaluating investments in IT'", Journal of Information Technology, Vol. 9 No. 3, pp. 239-243.

Fink, L. (2011), "How do IT capabilities create strategic value? Toward greater integration of insights from reductionistic and holistic approaches", European Iournal of Information Svstems, Vol. 20 No. 1, pp. 16-33.

Gimun, K., Bongsik, S., Kyung Kyu, K. and Ho Geun, L. (2011), "IT capabilities, process-oriented dynamic capabilities, and firm financial performance", Lournal of the Association for Information Svstems, Vol. 12 No. 7, pp. 487-517.

Goldspink, C. and Kay, R. (2010), "Emergence in organizations: the reflexive turn", Emergence: Complexity \& Organization, Vol. 12 No. 3, pp. 47-63.

Grover, V. and Kohli, R. (2012), "Cocreating IT value: new capabilities and metrics for multifirm environments”, MIS Quarterlv, Vol. 36 No. 1, pp. 225-232.

Helfat, C.E. and Peteraf, M.A. (2003), "The dynamic resource-based view: capability lifecycles", Strategic Management Iournal, Vol. 24 No. 10, pp. 997-1010.

Helfat, C.E., Finkelstein, S., Mitchell, W., Peteraf, M., Singh, H., Teece, D. and Winter, S. (2007), Dynamic Capabilities: Understanding Strategic Change in Organizations, Blackwell, Place, Oxford.

Ifinedo, P. (2007), "Interactions between organizational size, culture, and structure and some IT factors in the context of ERP success assessment: an exploratory investigation", The Iournal of Computer Information Systems, Vol. 47 No. 4, pp. 28-44. 
Jackson, M.C. (2006), "Creative holism: a critical systems approach to complex problem situations", Systems Research and Behavioral Science, (formerly Systems Research), Vol. 23 No. 5, pp. 647-657.

Jisc (2013), “Transformations programme”, available at: www.webarchive.org.uk/wayback/ archive/20140614021602;www.jisc.ac.uk/whatwedo/programmes/transformations.aspx (accessed 18 June 2015).

Kaplan, R.S. and Norton, D.P. (1992), "The balanced scorecard - measures that drive performance", Harvard Business Review, Vol. 70 No. 1, pp. 71-79.

Kearns, G. and Sabherwal, R. (2007), "Strategic alignment between business and information technology: a knowledge-based view of behaviors, outcome, and consequences", Iournal of Management Information Systems, Vol. 23 No. 3, pp. 129-162.

Kling, R. (2003), "Critical professional education about information and communications technologies and social life", Information Technology \& People, Vol. 16 No. 4, pp. 394-418.

Kohli, R. and Grover, V. (2008), "Business value of IT: an essay on expanding research directions to keep up with the times", Iournal of the Association for Information Svstems, Vol. 9 No. 1, pp. 23-39.

Lado, A.A. and Wilson, M.C. (1994), "Human resource systems and sustained competitive advantage: a competency-based perspective", Academv of Management Review, Vol. 19 No. 4, pp. 699-727.

Laszlo, E. and Laszlo, A. (1997), "The contribution of the systems sciences to the humanities", Svstems Research and Behavioral Science. (formerlv Svstems Research), Vol. 14 No. 1, pp. 5-19.

Lavalle, S., Lesser, E., Shockley, R., Hopkins, M.S. and Kruschwitz, N. (2011), "Special report: analytics and the new path to value", MIT Sloan Management Review, Vol. 52 No. 2, pp. 22-32.

Lawson, B. and Samson, D. (2001), "Developing innovation capability in organisations: a dynamic capabilities approach", International Journal of Innovation Management, Vol. 5 No. 3, pp. $377-400$.

Leavitt, H.J. and Whisler, T.L. (1958), "Management in the 1980's", Harvard Business Review, Vol. 36 No. 6, pp. 41-48.

Leiblein, M.J. (2011), "What do resource- and capability-based theories propose?", Lournal of Management, Vol. 37 No. 4, pp. 909-932.

Lim, J.-H., Stratopoulos, T.C. and Wirjanto, T.S. (2011), "Path dependence of dynamic information technology capability: an empirical investigation", Lournal of Management Information Svstems, Vol. 28 No. 3, pp. 45-84.

Magretta, J. (1998), “The power of virtual integration: an interview with Dell Computer's Michael Dell", Harvard Business Review, Vol. 76 No. 2, pp. 72-84.

Melville, N., Kraemer, K. and Gurbaxani, V. (2004), "Information technology and organizational performance: an integrative model of IT business value", MIS Quarterly, Vol. 28 No. 2, pp. 283-322.

Midgley, G. (2000), Svstemic Intervention: Philosophy. Methodology and Practice, Kluwer Academic/Plenum Publishers, Place, London.

Miller, D. (1996), “Configurations revisited”, Strategic Management Iournal, Vol. 17 No. 7, pp. 505-512.

Miller, D. (2003), "An asymmetry-based view of advantage: towards an attainable sustainability", Strategic Management Iournal, Vol. 24 No. 10, pp. 961-976.

Mishra, A.N., Konana, P. and Barua, A. (2007), "Antecedents and consequences of internet use in procurement: an empirical investigation of US manufacturing firms", Information Systems Research, Vol. 18 No. 1, pp. 103-120. 
ITP

29,3

Mukhopadhyay, T., Kekre, S. and Kalathur, S. (1995), "Business value of information technology: a study of electronic data interchange”, MIS Quarterlv, Vol. 19 No. 2, pp. 137-156.

Mulej, M. (2007), "Systems theory: a worldview and/or a methodology aimed at requisite holism/ realism of humans' thinking, decisions and action", Svstems Research \& Behavioral Science, Vol. 24 No. 3, pp. 347-357.

Nevo, S. and Wade, M. (2010), "The formation and value of IT-enabled resources: antecedents and consequences of synergistic relationships", MIS Quarterly, Vol. 34 No. 1, pp. 163-183.

Nolan, R. and Mcfarlan, F.W. (2005), "Information technology and the board of directors", Harvard Business Review, Vol. 83 No. 10, pp. 96-106.

Oh, W. and Pinsonneault, A. (2007), "On the assessment of the strategic value of information technologies: conceptual and analytical approaches”, MIS Quarterlv, Vol. 31 No. 2, pp. 239-265.

Orlikowski, W.J. (2007), "Sociomaterial practices: exploring technology at work", Organization Studies, Vol. 28 No. 9, pp. 1435-1448.

Orlikowski, W.J. and Scott, S.V. (2008), "Sociomateriality: challenging the separation of technology, work and organization", The Academv of Management Annals, Vol. 2 No. 1, pp. 433-474.

Peteraf, M.A. (1993), "The cornerstones of competitive advantage: a resource-based view", Strategic Management Journal, Vol. 14 No. 3, pp. 179-191.

Piccoli, G. and Ives, B. (2005), "IT-dependent strategic initiatives and sustained competitive advantage: a review and synthesis of the literature", MIS Quarterlv, Vol. 29 No. 4, pp. 747-776.

Pitelis, C.N. and Teece, D.J. (2010), "Cross-border market co-creation, dynamic capabilities and the entrepreneurial theory of the multinational enterprise", Industrial \& Corporate Change, Vol. 19 No. 4, pp. 1247-1270.

Porter, M.E. and Millar, V.E. (1985), "How information gives you competitive advantage", Harvard Business Review, Vol. 63 No. 4, pp. 149-160.

Radhakrishnan, A., Zu, X. and Grover, V. (2008), "A process-oriented perspective on differential business value creation by information technology: an empirical investigation", Omega, Vol. 36 No. 6, pp. 1105-1125.

Ravichandran, T., Liu, Y., Han, S. and Hasan, I. (2009), "Diversification and firm performance: exploring the moderating effects of information technology spending", Iournal of Management Information Sustems, Vol. 25 No. 4, pp. 205-240.

Ray, G., Barney, J.B. and Muhanna, W.A. (2004), "Capabilities, business processes, and competitive advantage: choosing the dependent variable in empirical tests of the resource-based view", Strategic Management Iournal, Vol. 25 No. 1, pp. 23-37.

Roberts, N. and Grover, V. (2012), "Leveraging information technology infrastructure to facilitate a firm's customer agility and competitive activity: an empirical investigation”, Iournal of Management Information Svstems, Vol. 28 No. 4, pp. 231-270.

Schwarz, A., Kalika, M., Kefi, H. and Schwarz, C. (2010), “A dynamic capabilities approach to understanding the impact of IT-enabled businesses processes and IT-business alignment on the strategic and operational performance of the firm", Communications of the Association for Information Systems, Vol. 26 No. 1, pp. 57-84.

Scott-Morton, M. (1995), "Emerging organizational forms: work and organization in the 21st century”, Eurobean Management Journal, Vol. 13 No. 4, pp. 339-345.

Shpilberg, D., Berez, S., Puryear, R. and Shah, S. (2007), "Avoiding the alignment trap in information technology”, MIT Sloan Management Review, Vol. 49 No. 1, pp. 51-58.

Tanriverdi, H. (2006), "Formance effects of information technology synergies in multibusiness firms", MIS Quarterlv, Vol. 30 No. 1, pp. 57-77. 
Tanriverdi, H. and Uysal, V.B. (2011), "Cross-business information technology integration and acquirer value creation in corporate mergers and acquisitions", Information Systems Research, Vol. 22 No. 4, pp. 703-720.

Teece, D.J. (2007), "Explicating dynamic capabilities: the nature and microfoundations of (sustainable) enterprise performance", Strategic Management Journal, Vol. 28 No. 13, pp. 1319-1350.

Teece, D.J., Pisano, G. and Shuen, A. (1997), "Dynamic capabilities and strategic management", Strategic Management Journal, Vol. 18 No. 7, pp. 509-533.

Ulrich, W. (1993), "Some difficulties of ecological thinking, considered from a critical systems perspective: a plea for critical holism", Systemic Practice and Action Research, Vol. 6 No. 6, pp. 583-611.

Volkoff, O., Strong, D.M. and Elmes, M.B. (2007), "Technological embeddedness and organizational change", Organization Science, Vol. 18 No. 5, pp. 832-848.

Von Bertalanffy, L. (1950), "The theory of open systems in physics and biology”, Science, Vol. 111 No. 2872, pp. 23-29.

Wade, M. and Hulland, J. (2004), "The resource-based view and information systems research: review, extension, and suggestions for future research", MIS Quarterlv, Vol. 28 No. 1, pp. 107-142.

Wagner, H.-T., Beimborn, D. and Weitzel, T. (2014), "How social capital among information technology and business units drives operational alignment and IT business value", Lournal of Management Information Svstems, Vol. 31 No. 1, pp. 241-272.

Watson, H.J. (2014), "Tutorial: big data analytics: concepts, technologies, and applications", Communications of the Association for Information Systems, Vol. 34 No. 1, pp. 1247-1268.

Weetman, R. (2009), "Emergence is not always 'good'”, Emergence: Complexity \& Organization, Vol. 11 No. 2, pp. 87-91.

Wernerfelt, B. (1984), “A resource-based view of the firm”, Strategic Management Journal, Vol. 5 No. 2, pp. 171-180.

Wiengarten, F., Humphreys, P., Cao, G. and Mchugh, M. (2013), "Exploring the important role of organizational factors in IT business value: taking a contingency perspective on the resource-based view", International Iournal of Management Reviews, Vol. 15 No. 1, pp. 30-46.

Zahra, S.A., Sapienza, H.J. and Davidsson, P. (2006), "Entrepreneurship and dynamic capabilities: a review, model and research agenda", Journal of Management Studies, Vol. 43 No. 4, pp. 917-955.

Zammuto, R.F., Griffith, T.L., Majchrzak, A., Dougherty, D.J. and Faraj, S. (2007), "Information technology and the changing fabric of organization”, Organization Science, Vol. 18 No. 5, pp. 749-762.

\section{Corresponding author}

Guangming Cao can be contacted at: guangming.cao@beds.ac.uk

For instructions on how to order reprints of this article, please visit our website:

www.emeraldgrouppublishing.com/licensing/reprints.htm

Or contact us for further details: permissions@emeraldinsight.com 